\title{
Effects of COVID-19 pandemic on pediatric kidney transplant in the United States
}

\author{
Olga Charnaya ${ }^{1}$ (D) $\cdot$ Teresa Po-Yu Chiang $^{2}$ (D) $\cdot$ Richard Wang $^{3} \cdot$ Jennifer D. Motter ${ }^{2}$ (D) B Bian J. Boyarsky ${ }^{2}$ (D) \\ Elizabeth A. King ${ }^{2}$ - William A. Werbel ${ }^{3}$ (D) Christine M. Durand ${ }^{3}$ (D) Robin K. Avery $^{3}$ (D) - Dorry L. Segev Rev $^{2,4}$ (D) \\ Allan B. Massie ${ }^{2,4}$ (D) Jacqueline M. Garonzik-Wang ${ }^{2}$ (D)
}

Received: 1 September 2020 / Accepted: 7 September 2020 / Published online: 26 September 2020

(C) IPNA 2020

\begin{abstract}
Background In March 2020, COVID-19 infections began to rise exponentially in the USA, placing substantial burden on the healthcare system. As a result, there was a rapid change in transplant practices and policies, with cessation of most procedures. Our goal was to understand changes to pediatric kidney transplantation (KT) at the national level during the COVID-19 epidemic. Methods Using SRTR data, we examined changes in pediatric waitlist registration, waitlist removal or inactivation, and deceased donor and living donor (DDKT/LDKT) events during the start of the disease transmission in the USA compared with the same time the previous year.

Results We saw an initial decrease in DDKT and LDKT by $47 \%$ and $82 \%$ compared with expected events and then a continual increase, with numbers reaching expected prepandemic levels by May 2020. In the early phase of the pandemic, waitlist inactivation and removals due to death or deteriorating condition rose above expected values by $152 \%$ and $189 \%$, respectively. There was a statistically significant decrease in new waitlist additions (IRR 0.490 .650 .85 ) and LDKT (IRR $0.170 .38_{0.84}$ ) in states with high vs. low COVID activity. Transplant recipients during the pandemic were more likely to have received a DDKT, but had similar calculated panel-reactive antibody (cPRA) values, waitlist time, and cause of kidney failure as before the pandemic. Conclusions The COVID-19 pandemic initially reduced access to kidney transplantation among pediatric patients in the USA but has not had a sustained effect.
\end{abstract}

Keywords Kidney transplantation $\cdot$ Registry analysis $\cdot$ Pediatrics $\cdot$ Donation $\cdot$ Infectious agents-viral

\section{Abbreviations}

COVID-19 Coronavirus disease 2020

KT Kidney transplant

LDKT Live donor kidney transplantation

Olga Charnaya

ocharna1@jhmi.edu

1 Department of Pediatrics, Johns Hopkins University School of Medicine, 200 N Wolfe St., Room 3055, Baltimore, MD 21287, USA

2 Department of Surgery, Johns Hopkins University School of Medicine, Baltimore, MD, USA

3 Department of Medicine, Johns Hopkins University School of Medicine, Baltimore, MD, USA

4 Department of Epidemiology, Johns Hopkins School of Public Health, Baltimore, MD, USA

5 Scientific Registry of Transplant Recipients, Minneapolis, MN, USA

$\begin{array}{ll}\text { DDKT } & \text { Deceased donor transplantation } \\ \text { CKD 5 } & \text { Stage 5 chronic kidney disease } \\ \text { SRTR } & \text { Scientific Registry of Transplant Recipients } \\ \text { OPTN } & \text { Organ Procurement and } \\ & \text { Transplantation Network } \\ \text { PMP } & \text { Per million population } \\ \text { DCD } & \text { Donation after circulatory death } \\ \text { IRR } & \text { Incidence rate ratio } \\ \text { ICU } & \text { Intensive care unit } \\ \text { OR } & \text { Operating room }\end{array}$

\section{Introduction}

As the death toll from COVID-19 in the USA surpasses 180,000 fatalities, the pandemic continues to place considerable burden on the health care system. Many transplant centers have been challenged to determine how to proceed with organ transplantation during a time of limited data and 
resources. These decisions have had profound implications for many patients awaiting transplantation, including the pediatric population, where kidney transplantation (KT) remains the optimal treatment for stage 5 chronic kidney disease (CKD 5) [1].

Adult KT has been significantly impacted by COVID-19, with reduced new waitlist addition and transplantation at many transplant centers across the nation $[2,3]$. A national survey of adult transplant centers showed that $72 \%$ had suspended live donor kidney transplants (LDKT) and $84 \%$ had placed significant restrictions on deceased donor kidney transplants (DDKT) by April 2020 [4]. The stringency of these restrictions varied by center, with more restrictive measures in areas with a higher incidence of COVID-19. Several reasons have been cited for these changes. First, there is concern that organ transplant recipients may be at a greater risk for acquiring and experiencing worse clinical outcomes due to COVID-19 infection [5-7]. Second, immunosuppressed KT recipients may have prolonged viral shedding and transmissibility, potentially posing a greater risk to public health $[8,9]$. Third, there is concern that hospitals will not have the resources to safely perform KT and provide the necessary postoperative care [10]. These changes are not without consequences; postponing KT can lead to a higher waitlist mortality, and diverting resources away from transplant recipients may worsen postoperative outcomes [11, 12].

It is unclear if the pandemic has resulted in similar challenges and restrictions for the pediatric population. For the most part, children are asymptomatic or have milder infection and fewer complications from COVID-19 compared with adult patients $[13,14]$. From the limited data available, it appears that disease severity even among immunocompromised children remains less severe than that of the general adult population and remains similar to healthy children [15-17]. Furthermore, while pediatric patients in general have less dialysis-associated morbidity and mortality compared with adults, delaying transplantation and prolonging time on dialysis is associated with increased morbidity and repetitive risk of COVID exposure during in-center dialysis sessions $[18,19]$. The response of the pediatric transplant community is likely different than adult practices and therefore needs to be studied separately.

To investigate center-specific changes in pediatric transplant practices during the COVID-19 pandemic, we used national registry data to quantify changes to KT waitlist registration, waitlist deaths or removal, and rates of DDKT and LDKT, between February and June 2020. We examined rates of these waitlist events among the overall patient population and evaluated for differences in patient characteristics during the COVID-19 pandemic. This information will allow us to better understand the pandemic's impact on the pediatric kidney transplant population.

\section{Methods}

\section{Data source}

This study used data from the Scientific Registry of Transplant Recipients (SRTR). The SRTR data system includes data on all donor, wait-listed candidates, and transplant recipients in the USA, submitted by the members of the Organ Procurement and Transplantation Network (OPTN). The Health Resources and Services Administration (HRSA), US Department of Health and Human Services provides oversight to the activities of the OPTN and SRTR contractors. This dataset has previously been described elsewhere [20].

\section{Study population}

For waitlist analysis, we included DDKT waitlist registrants aged 0-17 at time of listing (new listing; changed to inactive status; removed due to DDKT, LDKT, death or deteriorating condition, and other causes) were included. For analysis of transplant volume (DDKT, LDKT, DCD, national or regional import) recipients aged $0-17$ at time of transplant were included.

\section{National cumulative incidence of COVID-19}

National COVID-19 incidence data from January to June 2020 were extracted from USA FACTS (https:// usafacts.org/issues/coronavirus/) [21]. COVID-19 incidence is reported for all patients and not restricted to children, as many states are not providing data of infections by age groups. Based upon cumulative incidence of COVID-19 positive cases per-million state population (PMP) between March 15 and June 30 , states were stratified to be having low $(<8000$ PMP) or high ( $>8000$ PMP) COVID-19 burden. This cutoff was selected based on a visible difference in distribution of cumulative incidence of COVID-19 burden in the USA.

\section{Weekly counts of waitlist and transplant changes}

For each week (Sunday-Saturday) starting February 2, 2020, until June 27, 2020, we plotted cumulative counts of new waitlist additions, newly inactive patients, waitlist removal due to death or deteriorating condition, and waitlist removal due to transplant or other causes, using a Lowess smoothing function. We made similar plots for weekly counts of DDKT, LDKT, DCD donor, and regional and national imports. Weekly instead of daily counts were used due to the low number of daily events in pediatric patients to enable statistical analysis. On each plot, we also included the average counts during the same period in 2017-2019 as a visual reference of national prepandemic pediatric KT volume. 


\section{Statistical analysis}

We present characteristics of pediatric kidney transplant recipients separately in three time periods: January 1-March 15, 2020 ("Early"); March 16-April 30, 2020 ("Middle"); and May 1-June 30, 2020 ("Late"). Continuous variables were presented as median and interquartile range, and categorical variables were presented as counts and proportion. Comparison between groups were tested using KuskalWallis or Mann-Whitney $U$ tests, as appropriate, for continuous variables and Fisher's exact test for categorical variables. We used 2015 as reference year to calculate kidney donor profile index (KDPI) [22]. We obtained pediatric kidney waitlist changes or transplant volume by center, month, and year from January 1, 2016, to February 28, 2020, and constructed a mixed-effects Poisson regression with a center-level random intercept to obtain expected daily counts by center (monthly counts divided by 31 ), using methods previously described [23]. The expected counts of each time period were the sum of expected center-level counts during the corresponding length of time (March 15 to April 30: 47 days; May 1-June 30: 61 days). We then compared the observed and expected counts of each time period using chi square testing. We used an $\alpha$ of 0.05 to define statistical significance. All analyses were performed using Stata 16.0/MP for Linux (College Station, TX).

\section{Results}

\section{Characteristics of pediatric transplant patients during COVID-19}

Patient characteristics in three time periods ("Early" Jan 1Mar 15, 2020, "Middle" Mar 16-Apr 30, 2020, and "Late" May 1-Jun 30, 2020) were examined (Table 1). Patients who received a kidney transplant during the first COVID-19 peak in the USA, middle period, had similar waitlist time, cPRA, and blood type compared with early and late periods $(p>0.1)$. A higher proportion of Black patients received a transplant in the middle (30.6\%) compared with early $(13.1 \%)$ and late $(20.7 \%)$ periods $(p=0.28)$. Living donor transplants made up a smaller proportion of total transplants during the middle period $13.9 \%$, compared with $29.5 \%$ and $36.4 \%$ in early and late periods, respectively $(p=0.035)$. Median cold ischemia time (CIT) was longer in the middle period $10.2 \mathrm{~h}$ (IQR 6.517.4), compared with the early (9.0 $\mathrm{h}$ (IQR 4.0-13.2)) and late (7.6 h (IQR 2.4-10.7)) periods, $(p=0.02)$.

\section{Weekly count of waitlist changes}

National weekly pediatric KT waitlist additions ranged from 7 to 41 cases per week between February 2 and June 30, 2020.
There was a trend of decreasing new pediatric DDKT registrations, following the national rise of COVID-19 cases midMarch. Since April, none of the weekly pediatric KTs exceeded 21, the 2017-2019 average counts for the same period (Fig. 1a). The numbers of registrants who changed to inactive status also increased in March, with $77.2 \%$ of registrants who changed to inactive status in the third and fourth week of March indicating COVID-19 as reason of inactivation (Fig. 1c). COVID-19 was added as a refusal code or cause for change in status in UNET on March 25, 2020; however, this classification does not differentiate new COVID-19 infection in the patient vs. precaution secondary to the pandemic. Percentage of inactive waitlist registrants rose from 72 to 77\% between March 1 and April 15 and remained elevated above previous baseline thereafter (Fig. 1d). We observed an increasing trend in waitlist removal due to death or deteriorating condition since March, followed by a trend that returned to previous benchmarks by late-April (Fig. 1b).

\section{Weekly count of transplant events}

The national weekly pediatric DDKT volume ranged from 0 to 16 cases per week between February 1 and June 30, 2020. On average, the weekly DDKT volume in 2017-2019 was 9.6 cases. Between mid-March and the end of June 2020, DDKT volume remained lower than 9.6 except for 4 weeks out of the 15 during observation. There was a trend of decreasing DDKT and LDKT volume seen since March, followed by increase from mid-April to end of June (Fig. 2a, b). For LDKT, the weekly volumes were never above the 2017-2019 average between mid-March and May 31 but consistently surpassed this volume in June 2020 (Fig. 2b).

\section{Regional and national imports}

Overall numbers of regional and national imports were extremely low ( $0-4$ per week), with average $<1$ import per week in 2017-2019 (Fig. 2c). During the early period of COVID-19 disease activity in the USA, imports were more common than in previous years. As the pandemic progressed, there was a decline in imports; however, the average number of imports continues to remain higher than previous years.

\section{Comparing the observed and predicted waitlist changes}

The overall observed national volume of waitlist registration was lower $(-13.3 \%, p=0.021)$ and change to inactive waitlist status was higher $(57.2 \%, p<0.001)$ compared with the expected volume during March 15-June 30, 2020 (Table 2). When stratified into the earlier (March 15-April 30, 2020) and the latter (May 1-June 30, 2020) periods, 6 candidates were removed from the waitlist during the earlier period due to 
Table 1 Patient and donor characteristics broken down by three time periods of COVID-19 activity in 2020

\begin{tabular}{|c|c|c|c|c|}
\hline$N$ & $\begin{array}{l}\text { Early Jan 1-Mar } 15 \\
122\end{array}$ & $\begin{array}{l}\text { Middle Mar 15-Apr } 30 \\
36\end{array}$ & $\begin{array}{l}\text { Late May 1-Jun } 30 \\
121\end{array}$ & $p$ value \\
\hline \multicolumn{5}{|l|}{ Recipient factors } \\
\hline Wait time (IQR) & $202.5(81,618)$ & $201.5(42.5,547)$ & $227(92,495)$ & 0.87 \\
\hline Female Sex & $59(48.4 \%)$ & $14(38.9 \%)$ & $56(46.3 \%)$ & 0.61 \\
\hline Race & & & & 0.28 \\
\hline White & $95(77.9 \%)$ & $21(58.3 \%)$ & $86(71.1 \%)$ & \\
\hline Black & $16(13.1 \%)$ & $11(30.6 \%)$ & $25(20.7 \%)$ & \\
\hline Asian & $7(5.7 \%)$ & $3(8.3 \%)$ & $8(6.6 \%)$ & \\
\hline Others & $4(3.3 \%)$ & $1(2.8 \%)$ & $2(1.7 \%)$ & \\
\hline ABO Blood Type & & & & 0.94 \\
\hline Type O & $70(57.4 \%)$ & $21(58.3 \%)$ & $71(58.7 \%)$ & \\
\hline Type A & $30(24.6 \%)$ & $10(27.8 \%)$ & $34(28.1 \%)$ & \\
\hline Type B & $16(13.1 \%)$ & $4(11.1 \%)$ & $13(10.7 \%)$ & \\
\hline Type AB & $6(4.9 \%)$ & $1(2.8 \%)$ & $3(2.5 \%)$ & \\
\hline Primary diagnosis & & & & 0.065 \\
\hline Glomerulonephritis & $21(17.2 \%)$ & $2(5.6 \%)$ & $17(14.0 \%)$ & \\
\hline FSGS & $15(12.3 \%)$ & $5(13.9 \%)$ & $15(12.4 \%)$ & \\
\hline Hypoplasia & $32(26.2 \%)$ & $7(19.4 \%)$ & $14(11.6 \%)$ & \\
\hline Obstructive & $19(15.6 \%)$ & $8(22.2 \%)$ & $19(15.7 \%)$ & \\
\hline Polycystic & $9(7.4 \%)$ & $2(5.6 \%)$ & $18(14.9 \%)$ & \\
\hline Others & $26(21.3 \%)$ & $12(33.3 \%)$ & $38(31.4 \%)$ & \\
\hline cPRA, mean (SD) & $12 \%(24)$ & $9 \%(26)$ & $7 \%(20)$ & 0.29 \\
\hline$c P R A \neq 0$, median $(\mathrm{IQR})$ & $44 \%(5,64)(n=36)$ & $61 \%(5,99)(n=7)$ & $11 \%(0,52)(n=31)$ & 0.087 \\
\hline $\mathrm{cPRA} \geq 0.2$ & $23(18.9 \%)$ & $4(11.1 \%)$ & $15(12.4 \%)$ & 0.33 \\
\hline \multicolumn{5}{|l|}{ Donor factors } \\
\hline Age (year), median (IQR) & $28(20,34)$ & $25.50(21.50,32)$ & $28(22,35)$ & 0.68 \\
\hline Female gender & $52(42.6 \%)$ & $16(44.4 \%)$ & $51(42.1 \%)$ & 0.97 \\
\hline Living donor & $36(29.5 \%)$ & $5(13.9 \%)$ & $44(36.4 \%)$ & $0.035^{*}$ \\
\hline Race & & & & 0.55 \\
\hline White & $103(84.4 \%)$ & $29(80.6 \%)$ & $102(84.3 \%)$ & \\
\hline Black & $13(10.7 \%)$ & $3(8.3 \%)$ & $15(12.4 \%)$ & \\
\hline Asian & $3(2.5 \%)$ & $3(8.3 \%)$ & $3(2.5 \%)$ & \\
\hline Other race & $3(2.5 \%)$ & $1(2.8 \%)$ & $1(0.8 \%)$ & \\
\hline KDPI & $n=86$ & $\mathrm{n}=31$ & $n=77$ & \\
\hline Median (IQR) & $13.73(7.65,26.72)$ & $14.57(5.93,28.99)$ & $17.56(9.71,28.34)$ & 0.46 \\
\hline Mean (SD) & $17.30(13.46)$ & $17.38(12.63)$ & $19.21(12.18)$ & 0.61 \\
\hline Cold ischemic time (hours), median (IQR) & $9.0(4.0,13.2)(n=121)$ & $10.2(6.5,17.5)(n=34)$ & $7.6(2.4,10.7)(n=57)$ & $0.021 *$ \\
\hline
\end{tabular}

$I Q R$ interquartile range, $F S G S$ focal segmental glomerulosclerosis, $c P R A$ calculated panel-reactive antibody, $S D$ standard deviation, $K D P I$ kidney donor profile index

$* p<0.05$

death or deteriorated condition, which was $189 \%$ more than the expected 2.1 cases $(p=0.005)$. Similarly, 83 candidates had changed to inactive status during the earlier period, which was $152 \%$ more than the expected 32.9 cases $(p<0.001)$. In both cases, the significance was not achieved in the latter period $(11.3 \%, p=0.3$ and $-11.1 \%, p=0.5$, respectively). Contrarily, the observed counts of new waitlist registration were $23.8 \%$ lower compared with the expected during the latter period $(p=0.002)$, though not significantly different in the earlier period $(0.4 \%, p=1.0)$.

\section{Comparing the observed and predicted transplant events}

There were 157 pediatric KTs performed during March 15June 30, 2020 (108 DDKT, 49 LDKT), which was 22.8\% 


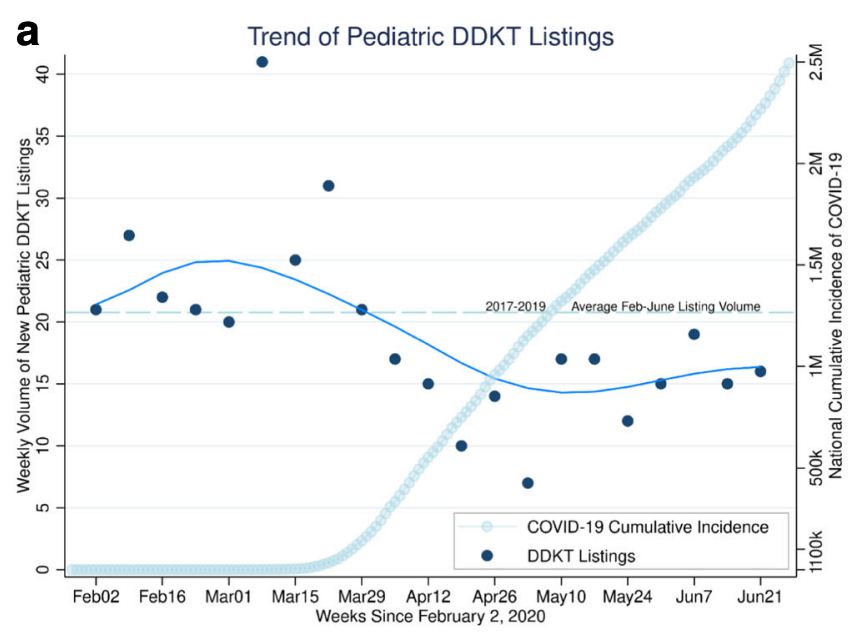

b
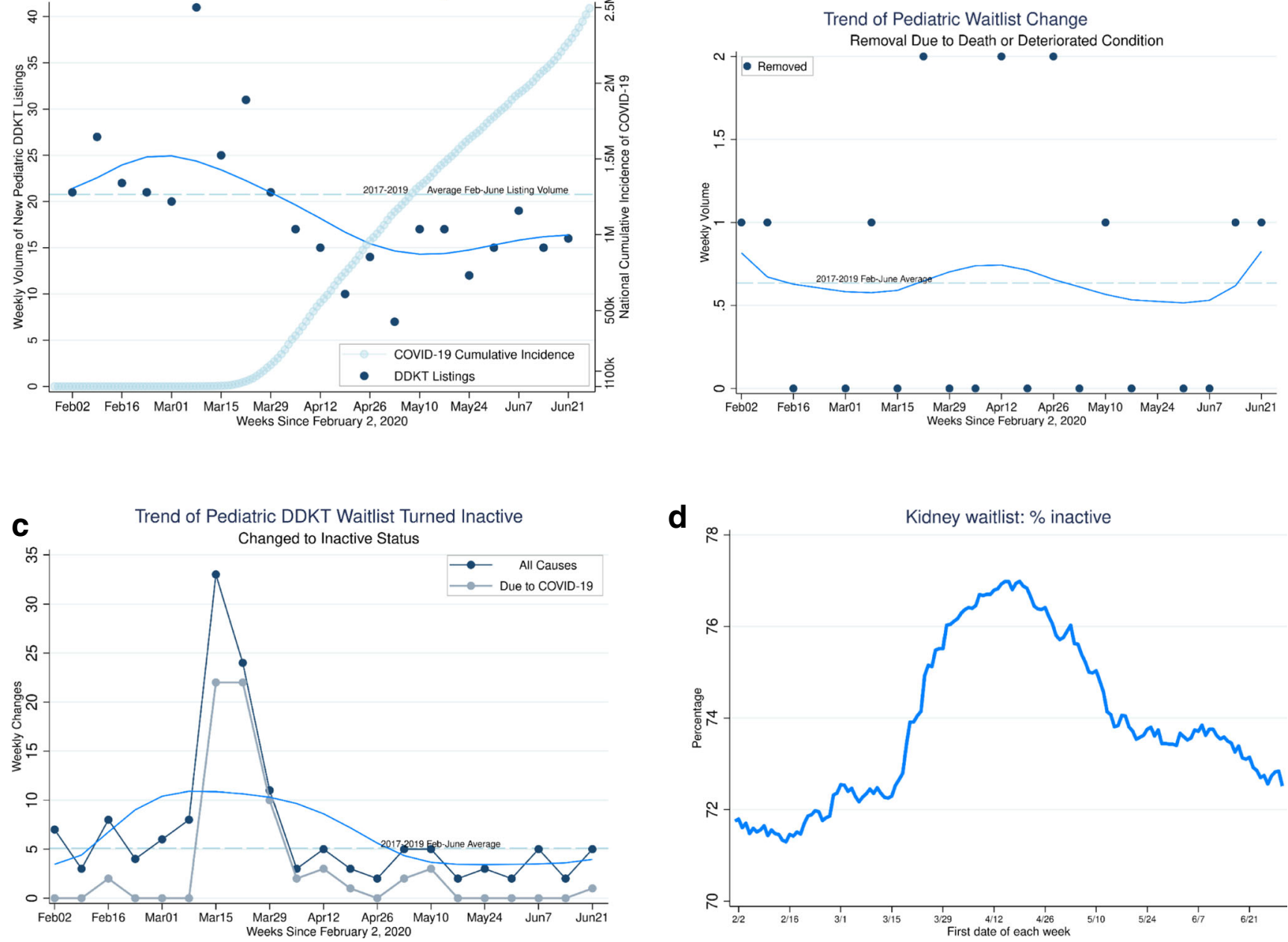

** Removal due to COVID-19 was listed at the reason for status change in UNET. This does not distinguish between infection or precaution secondary to the pandemic.

Fig. 1 Pediatric patient deceased donor KT waitlist status change; a new waitlist additions, $\mathbf{b}$ removal due to death or deteriorating condition, $\mathbf{c}$ changed to inactive status, $\mathbf{d}$ percentage inactive

fewer than the expected 203.3 cases $(p=0.001)$. The 108 DDKT performed during this period was $29.2 \%$ fewer than the expected 103.1 cases $(p=0.03)$, whereas the 49 LDKTs was not significantly different from the expected 64.2 cases $(p=0.058)$. When stratified to the earlier and the latter COVID-19 eras, the observed DDKT, LDKT, and combined total transplant were all significantly less than expected in the earlier era (total: 36 vs. $88.5,-59.3 \%, p<0.001$; LDKT: 5 vs. $27.9,-82.1 \%, p<0.001$; DDKT: 31 vs. $59.1 \%,-47.6 \%$, $p<0.001$ ), but not during the latter period.

\section{Regional differences in transplant practice and waitlist death by COVID-19 burden}

Centers situated in states with high COVID-19 burden (NY, NJ, RI, MA, DC, CT, LA, DE, IL, MD, AZ, NE, IA, NS) between March 15 and June 30 had significantly fewer new waitlist registrations (incidence rate ratio (IRR): 0.490 .650 .85 ) and LDKT (IRR: $0.170 .38_{0.84}$ ) compared with centers in states with low burden (IRR: 0.820 .94 1.08) (Table 3). There were no differences in the proportion of expected DDKT and waitlist death between centers in states with high and low COVID-19 burden.

\section{Discussion}

In this national registry study of pediatric KT trends during the COVID-19 pandemic, we found an increase in patients being changed to inactive status of $152 \%$, an increase in mortality on the waitlist by $189 \%$, a decrease in DDKT by $48 \%$, and LDKT by $82 \%$ compared with expected in the early COVID-19 time period without a significant impact on new waitlist additions. The COVID-19 pandemic has substantially limited access to KT and increased waitlist mortality in pediatric patients. 
Fig. 2 Pediatric transplant events cumulatively by week starting Feb 2, 2020; a DDKT, b LDKT, c

Regional and National imports

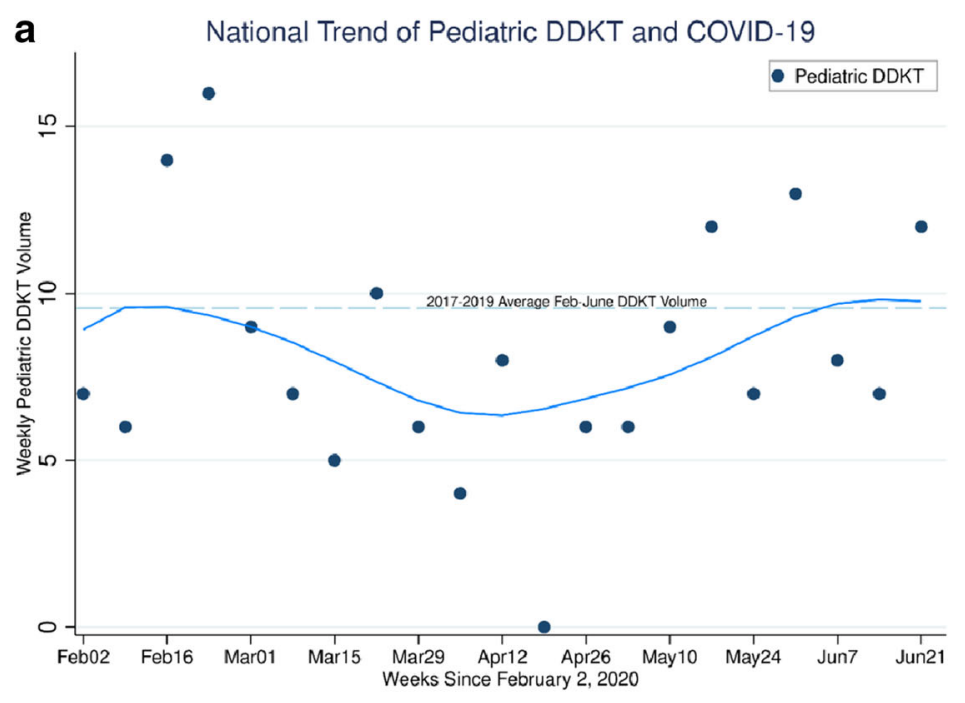

b

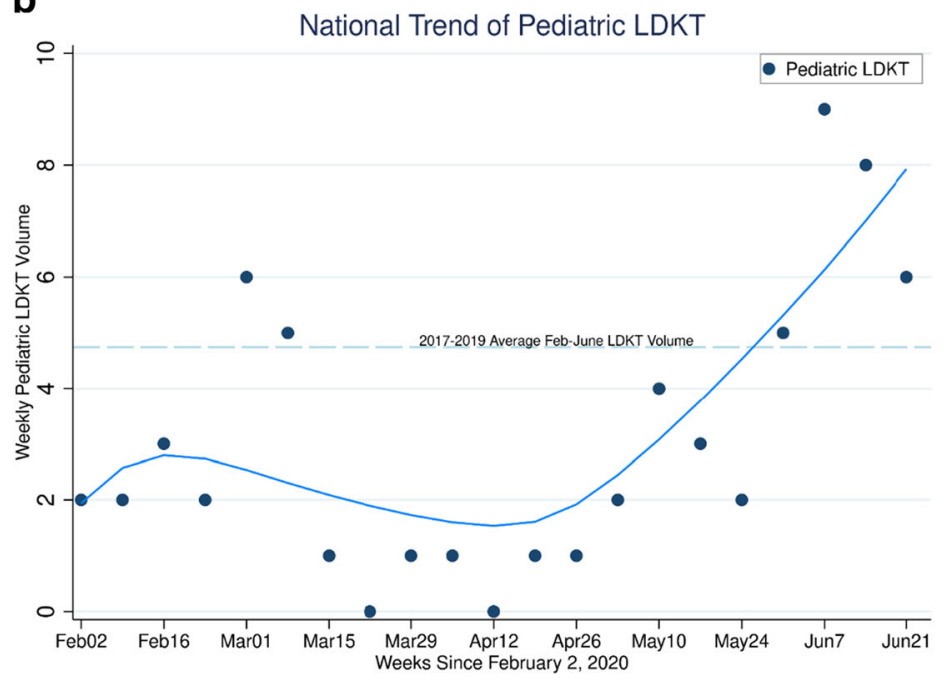

C

National Trend of Pediatric DDKT

National or Regional Import

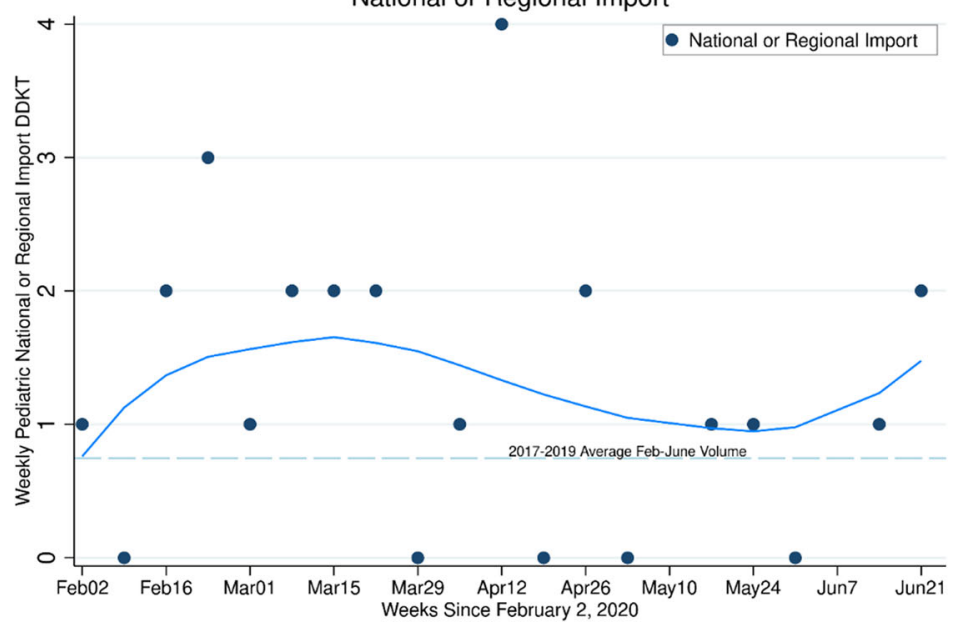


Table 2 Observed compared to expected events in early and later COVID-19 eras of waitlist changes and transplant events

\begin{tabular}{|c|c|c|c|c|c|c|c|c|c|c|c|c|c|}
\hline \multirow{2}{*}{\multicolumn{2}{|c|}{$\begin{array}{l}\text { Waitlist changes (pediatric } \\
\text { age at listing) }\end{array}$}} & \multicolumn{4}{|c|}{ March 15-April 30, 2020} & \multicolumn{4}{|c|}{ May 1-June 30, 2020} & \multicolumn{4}{|l|}{ Total } \\
\hline & & Observed & Expected & $\%$ change & $p$ value & Observed & Expected & $\%$ change & $p$ value & Observed & Expected & $\%$ change & $p$ value \\
\hline New listing & & 132 & 131.5 & 0.4 & 0.967 & 130 & 170.7 & -23.8 & 0.002 & 262 & 302.2 & -13.3 & 0.021 \\
\hline \multirow[t]{3}{*}{ Causes of removal } & Death & 6 & 2.1 & 189.0 & 0.006 & 3 & 2.7 & 11.3 & 0.852 & 9 & 4.8 & 88.7 & 0.053 \\
\hline & DDKT & 42 & 64.5 & -34.9 & 0.005 & 93 & 83.7 & 11.1 & 0.309 & 135 & 148.2 & -8.9 & 0.279 \\
\hline & LDKT & 5 & 27.8 & -82.0 & $<0.01$ & 44 & 36.1 & 21.9 & 0.188 & 49 & 63.9 & -23.3 & 0.062 \\
\hline \multicolumn{2}{|c|}{ Changed to inactive status } & 83 & 32. & 152.0 & $<0$ & 38 & 42. & -1 & 0.468 & 119 & 75 & 57 & $<0.01$ \\
\hline \multirow{2}{*}{\multicolumn{2}{|c|}{$\begin{array}{l}\text { Transplant (pediatric age } \\
\text { at transplant) }\end{array}$}} & \multicolumn{4}{|c|}{ March 15-April 30, 2020} & \multicolumn{4}{|c|}{ May 1-June 30, 2020} & \multicolumn{4}{|l|}{ Total } \\
\hline & & Obse & Expected & $\%$ change & $p$ value & Obser & Expected & $\% \mathrm{ch}$ & $p$ value & Observed & Expected & nge & $p$ value \\
\hline Total transplant & & 36 & 88.5 & -59.3 & $<0.01$ & 121 & 114.8 & 5.4 & 0.566 & 157 & 203.3 & -22.8 & 0.001 \\
\hline LDKT & & 5 & 27.9 & -82.1 & $<0.01$ & 44 & 36.3 & 21.3 & 0.199 & 49 & 64.2 & -23.7 & 0.058 \\
\hline DDKT & & 31 & 59.1 & -47.6 & $<0.01$ & 77 & 76.8 & 0.3 & 1.000 & 108 & 135.9 & -20.5 & 0.017 \\
\hline DCD & & 1 & 3.2 & -68.4 & 0.224 & 5 & 4.1 & 21.6 & 0.663 & 6 & 7.3 & -17.6 & 0.632 \\
\hline Regional or nationa & l import & 7 & 3.7 & 90.7 & 0.082 & 4 & 4.8 & -16.1 & 0.729 & 11 & 8.4 & 30.4 & 0.377 \\
\hline
\end{tabular}

$D D K T$ Deceased donor kidney transplant, $L D K T$ living donor kidney transplant, $D C D$ donation after circulatory death

Many transplant programs significantly altered their routine protocols and stopped performing kidney transplants, thereby restricting access to KT during the COVID-19 pandemic [4]. A recent registry of adult solid organ transplant (SOT) recipients infected with COVID-19 did not show any significant difference in mortality or morbidity compared with non-SOT patients [24]. While extensive data in pediatric SOT recipients is not available, several case reports show that pediatric SOT patients infected with COVID-19 showed only mild disease, even while on immunosuppressive therapy $[25,26]$. As children have different etiologies of kidney failure, different comorbidities, and seem to be affected differently by COVID-19, uniform policies affecting access to transplantation for both children and adults are not appropriate nor in the best interest of pediatric patients [16]. The increased mortality while on the waitlist that we showed in pediatric patients is a striking metric that supports the need for an individualized approach for pediatric KT patients. As pediatric KT events are relatively rare compared with adult $\mathrm{KT}$, this affords an opportunity for patient-level versus center-level decisions about risk and benefit of KT in a pandemic setting.

The reduction of transplant events in children seen during the middle (March 15-April 30, 2020) COVID-19 era was likely secondary to a combination of factors. As hospitals shifted resources to treat COVID-19 patients, there was a decrease in available ICU beds for postoperative management and restrictions on operating room availability. Pediatric KT patients require intensive postoperative care, which may strain healthcare systems already overburdened by COVID-19 patients [27]. In addition, there was a notable decline in deceased donor organs recovered during March and April [28]. Shortages of COVID-19 testing or delayed results for deceased donors may have impacted center willingness to accept an organ from what would otherwise be an acceptable donor. As testing capacity increased across the country, this limitation was ameliorated. Finally, many centers stopped or significantly reduced elective and nonemergent surgical procedures, which likely had a significant impact on LDKT. For pediatric patients scheduled to receive an LDKT, it should be argued that transplant is not truly an elective procedure whether preemptive or not. Dialysis initiation would require at least one surgical procedure to establish dialysis access, and initiation or continuation of hemodialysis would result in a much higher COVID-19 exposure risk [29]. While peritoneal dialysis patients do not require frequent in-center visits and thereby can have minimal healthcare exposure, especially with the advancement of telehealth capabilities across the country, the benefit of transplant over dialysis has been well established in the pediatric CKD 5 population [30,31]. As healthcare centers lifted restrictions on elective cases and practice patterns changed, there was a large increase in LDKT in June 2020 suggesting cases had been postponed due to the pandemic.

Table 3 Observed center-level events as a proportion of expected events, March 15-June 30, 2020

\begin{tabular}{|c|c|c|c|c|}
\hline COVID-19 rates & New listings & DDKT & LDKT & Waitlist death \\
\hline Overall & 0.770 .870 .98 & 0.660 .790 .96 & $0.580 .76_{1.01}$ & 0.981 .893 .63 \\
\hline Low & $0.820 .94_{1.08}$ & $0.660 .81 \quad 1.00$ & 0.660 .891 .20 & 0.841 .874 .16 \\
\hline High* & 0.490 .650 .85 & $0.480 .73 \quad 1.12$ & $0.170 .38_{0.84}$ & 0.621 .925 .96 \\
\hline
\end{tabular}

Italics denotes IRRs that are statistically significantly different from the IRR in states with low COVID-19 disease burden $(<8000$ cases PMP)

*States with high COVID-19 burden: NY, NJ, RI, MA, DC, CT, LA, DE, IL, MD, AZ, NE, IA, NS 
Our hypothesis that children who received a transplant during the peak of the pandemic would differ in some characteristics compared with prepandemic patients was not supported. There were no statistically significant differences in donor $\mathrm{KDPI}$, recipient cPRA, or etiology of CKD 5. While cold ischemia time in the middle time period was longer, this is unlikely to be a clinically significant difference. This is the first study to describe characteristics of donors and recipients receiving a KT during the pandemic.

As this is a registry study, we are limited in the information that is available for analysis and are not able to delve into granular details of waitlist removal or patient death. While transplant centers have mandatory reporting requirements to UNOS/OPTN, data transmission may be delayed due to center practices and pandemic effect on workflow. Nevertheless, we are able to make generalized conclusions about the effects of COVID-19 on access to KT in pediatric patients. We were unable to differentiate regional variability in transplant rates and waitlist changes due to the overall low number of events in pediatric patients.

In summary, we found that the COVID-19 pandemic has had a significant impact on pediatric KT waitlist mortality, waitlist registration, DDKT, and LDKT. Further studies to assess outcomes of pediatric patients who received a KT during this time are necessary to inform changes in policies and practices to optimize pediatric transplant outcomes and ensure access to this life-saving treatment.

Authors' contributions Charnaya, Chiang, Motter, Wang, and Massie participated in study design, analysis, and manuscript preparation. Boyarsky participated in study design and manuscript preparation. Wang, Motter, King, Werbel, Durand, and Segev contributed to significant review of the analysis and manuscript preparation.

Funding This work was supported by grant number KL2TR003099 (Charnaya) from Johns Hopkins Institute for Clinical and Translational Research (ICTR) as well as F32DK124941 (Boyarsky), K23DK11590801 (Garonzik-Wang), and K01DK101677 (Massie) from the National Institute of Diabetes and Digestive and Kidney Diseases (NIDDK) and K24AI144954 (Segev) from National Institute of Allergy and Infectious Diseases (NIAID)

Data availability Data is available for review upon request to the corresponding author.

\section{Compliance with ethical standards}

Conflict of interest The authors declare that they have no conflict of interest.

Ethics approval Approved by the institutional review board at Johns Hopkins University School of Medicine.

\section{Consent to participate Not applicable.}

Consent for publication Not applicable.
Code availability Not applicable.

Disclaimer The analyses described here are the responsibility of the authors alone and do not necessarily reflect the views or policies of the Department of Health and Human Services, nor does mention of trade names, commercial products or organizations imply endorsement by the US Government. The data reported here have been supplied by the Hennepin Healthcare Research Institute (HHRI) as the contractor for the Scientific Registry of Transplant Recipients (SRTR). The interpretation and reporting of these data are the responsibility of the author(s) and in no way should be seen as an official policy of or interpretation by the SRTR or the US Government.

\section{References}

1. Amaral S, Sayed BA, Kutner N, Patzer RE (2016) Preemptive kidney transplantation is associated with survival benefits among pediatric patients with end-stage renal disease. Kidney Int 90:1100 1108. https://doi.org/10.1016/j.kint.2016.07.028

2. Holshue ML, DeBolt C, Lindquist S, Lofy KH, Wiesman J, Bruce H, Spitters C, Ericson K, Wilkerson S, Tural A, Diaz G, Cohn A, Fox L, Patel A, Gerber SI, Kim L, Tong S, Lu X, Lindstrom S, Pallansch MA, Weldon WC, Biggs HM, Uyeki TM, Pillai SK (2020) First case of 2019 novel coronavirus in the United States. N Engl J Med 382:929-936. https://doi.org/10.1056/ NEJMoa2001191

3. Michaels MG, La Hoz RM, Danziger-Isakov L, Blumberg EA, Kumar D, Green M, Pruett TL, Wolfe CR (2020) Coronavirus disease 2019: implications of emerging infections for transplantation. Am J Transplant. https://doi.org/10.1111/ajt.15832

4. Boyarsky BJ, Po-Yu Chiang T, Werbel WA, Durand CM, Avery RK, Getsin SN, Jackson KR, Kernodle AB, Van Pilsum Rasmussen SE, Massie AB, Segev DL, Garonzik-Wang JM (2020) Early impact of COVID-19 on transplant center practices and policies in the United States. Am J Transplant. https://doi.org/ 10.1111/ajt.15915

5. Cheng Y, Luo R, Wang K, Zhang M, Wang Z, Dong L, Li J, Yao Y, Ge S, Xu G (2020) Kidney disease is associated with in-hospital death of patients with COVID-19. Kidney Int 97:829-838. https:// doi.org/10.1016/j.kint.2020.03.005

6. Fanelli V, Fiorentino M, Cantaluppi V, Gesualdo L, Stallone G, Ronco C, Castellano G (2020) Acute kidney injury in SARSCoV-2 infected patients. Crit Care 24:155. https://doi.org/10. 1186/s13054-020-02872-z

7. Banerjee D, Popoola J, Shah S, Ster IC, Quan V, Phanish M (2020) COVID-19 infection in kidney transplant recipients. Kidney Int 97: 1076-1082. https://doi.org/10.1016/j.kint.2020.03.018

8. Man Z, Jing Z, Huibo S, Bin L, Fanjun Z (2020) Viral shedding prolongation in a kidney transplant patient with COVID-19 pneumonia. Am J Transplant. https://doi.org/10.1111/ajt.15996

9. Fishman JA, Grossi PA (2020) Novel Coronavirus-19 (COVID19) in the immunocompromised transplant recipient: \#Flatteningthecurve. Am J Transplant. https://doi.org/10.1111/ ajt. 15890

10. Loupy A, Aubert O, Reese PP, Bastien O, Bayer F, Jacquelinet C (2020) Organ procurement and transplantation during the COVID19 pandemic. Lancet 395:e95-e96. https://doi.org/10.1016/s01406736(20)31040-0

11. Massie AB, Boyarsky BJ, Werbel WA, Bae S, Chow EK, Avery RK, Durand CM, Desai N, Brennan D, Garonzik-Wang JM, Segev DL (2020) Identifying scenarios of benefit or harm from kidney transplantation during the COVID-19 pandemic: a stochastic 
simulation and machine learning study. Am J Transplant. https:// doi.org/10.1111/ajt.16117

12. de Vries APJ, Alwayn IPJ, Hoek RAS, van den Berg AP, Ultee FCW, Vogelaar SM, Haase-Kromwijk B, Heemskerk MBA, Hemke AC, Nijboer WN, Schaefer BS, Kuiper MA, de Jonge J, van der Kaaij NP, Reinders MEJ (2020) Immediate impact of COVID-19 on transplant activity in the Netherlands. Transpl Immunol 61:101304. https://doi.org/10.1016/j.trim.2020.101304

13. Zimmermann $\mathrm{P}$, Curtis $\mathrm{N}$ (2020) Coronavirus infections in children including COVID-19: an overview of the epidemiology, clinical features, diagnosis, treatment and prevention options in children. Pediatr Infect Dis J 39:355-368. https://doi.org/10.1097/inf. 0000000000002660

14. Dong Y, Mo X, Hu Y, Qi X, Jiang F, Jiang Z, Tong S (2020) Epidemiology of COVID-19 among children in China. Pediatrics 145:e20200702. https://doi.org/10.1542/peds.2020-0702

15. Marlais M, Wlodkowski T, Vivarelli M, Pape L, Tönshoff B, Schaefer F, Tullus K (2020) The severity of COVID-19 in children on immunosuppressive medication. Lancet Child Adolesc Health 4:e17-e18. https://doi.org/10.1016/s2352-4642(20)30145-0

16. Zachariah P, Johnson CL, Halabi KC, Ahn D, Sen AI, Fischer A, Banker SL, Giordano M, Manice CS, Diamond R, Sewell TB, Schweickert AJ, Babineau JR, Carter RC, Fenster DB, Orange JS, McCann TA, Kernie SG, Saiman L (2020) Epidemiology, clinical features, and disease severity in patients with coronavirus disease 2019 (COVID-19) in a children's hospital in New York City, New York. JAMA Pediatr. https://doi.org/10.1001/ jamapediatrics.2020.2430

17. Melgosa M, Madrid A, Alvárez O, Lumbreras J, Nieto F, Parada E, Perez-Beltrán V (2020) SARS-CoV-2 infection in Spanish children with chronic kidney pathologies. Pediatr Nephrol. https://doi.org/ 10.1007/s00467-020-04597-1

18. Weaver DJ Jr, Somers MJG, Martz K, Mitsnefes MM (2017) Clinical outcomes and survival in pediatric patients initiating chronic dialysis: a report of the NAPRTCS registry. Pediatr Nephrol 32: 2319-2330. https://doi.org/10.1007/s00467-017-3759-4

19. Prezelin-Reydit M, Combe C, Harambat J, Jacquelinet C, Merville P, Couzi L, Leffondré K (2019) Prolonged dialysis duration is associated with graft failure and mortality after kidney transplantation: results from the French transplant database. Nephrol Dial Transplant 34:538-545. https://doi.org/10.1093/ndt/gfy039

20. Massie AB, Kucirka LM, Segev DL (2014) Big data in organ transplantation: registries and administrative claims. Am J Transplant 14:1723-1730. https://doi.org/10.1111/ajt.12777

21. USAFACTS (2020) Coronavirus Stats \& Data. https://usafacts.org/ issues/coronavirus/. Accessed 26 Aug 2020
22. Massie AB, Leanza J, Fahmy LM, Chow EKH, Desai NM, Luo X, King EA, Bowring MG, Segev DL (2016) A risk index for living donor kidney transplantation. Am J Transplant 16:2077-2084. https://doi.org/10.1111/ajt.13709

23. Boyarsky BJ, Werbel WA, Durand CM, Avery RK, Jackson KR, Kernodle AB, Snyder J, Hirose R, Massie IM, Garonzik-Wang JM, Segev DL, Massie AB (2020) Early national and center-level changes to kidney transplantation in the United States during the COVID-19 epidemic. Am J Transplant. https://doi.org/10.1111/ ajt.16167

24. Molnar MZ, Bhalla A, Azhar A, Tsujita M, Talwar M, Balaraman V, Sodhi A, Kadaria D, Eason JD, Hayek SS, Coca SG, Shaefi S, Neyra JA, Gupta S, Leaf DE Kovesdy CP, STOP, -COVID Investigators (2020) Outcomes of critically ill solid organ transplant patients with COVID-19 in the United States. Am J Transplant. https://doi.org/10.1111/ajt.16280

25. D'Antiga L (2020) Coronaviruses and immunosuppressed patients: the facts during the third epidemic. Liver Transpl 26:832-834. https://doi.org/10.1002/lt.25756

26. Bush R, Johns F, Acharya R, Upadhyay K (2020) Mild COVID-19 in a pediatric renal transplant recipient. Am J Transplant. https://doi. org/10.1111/ajt.16003

27. Pathak EB, Salemi JL, Sobers N, Menard J, Hambleton IR (2020) COVID-19 in children in the United States: intensive care admissions, estimated total infected, and projected numbers of severe pediatric cases in 2020. J Public Health Manag Pract 26:325-333. https://doi.org/10.1097/phh.0000000000001190

28. UNOS (2020) Number of deceased donors recovered in the US by week. https://public.tableau.com/shared/8MW3ZBGK9?:toolbar= $\mathrm{n} \&$ :display_count $=\mathrm{n} \&$ : origin $=\mathrm{viz} \_$share_link $\&$ : embed $=\mathrm{y}$. Accessed 6/23/2020

29. Ikizler TA, Kliger AS (2020) Minimizing the risk of COVID-19 among patients on dialysis. Nat Rev Nephrol 16:311-313. https:// doi.org/10.1038/s41581-020-0280-y

30. Lew SQ, Sikka N (2019) Operationalizing Telehealth for home dialysis patients in the United States. Am J Kidney Dis 74:95100. https://doi.org/10.1053/j.ajkd.2019.01.023

31. Verghese PS (2017) Pediatric kidney transplantation: a historical review. Pediatr Res 81:259-264. https://doi.org/10.1038/pr.2016. 207

Publisher's note Springer Nature remains neutral with regard to jurisdictional claims in published maps and institutional affiliations. 